\title{
“六艺” 与北师港浸大博雅教育和全人教育 \\ From the Confucius Six Arts to UIC's Liberal Education and Whole Person Education
}

郭海鹏 Guo Haipeng*

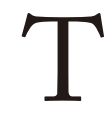
HIS article introduces basic concepts of Liberal Arts College, liberal education, general education and whole person education. It points out that the traditional Confucius education can be regarded as a Chinese liberal education and it shares the same goal as that of the western liberal education tradition. It also describes the philosophical and cultural background of Beijing Normal University-Hong Kong Baptist University United International College (UIC)'s whole-person oriented new liberal education and introduces how the ancient Confucius Six Arts have been revived in the past years as whole person education learning courses and activities on UIC campus.

北师港浸大（ UIC）的创校使命是在中国内地建立一所国际化 博雅大学, 扎根中国文化土壤, 发展一种以培育全人为导向的创新 博雅教育, 以为中国高等教育生态多元化作出贡献, 为中国和世界 培养面向二十一世纪的全球公民。本文简述博雅教育与全人教育一 系列基本概念，指出中国儒家传统的 “六经” 和 “六艺” 之教就是 一种古典的博雅教育和有中国特色的全人教育, 并介绍古老的 “六 艺”如何在北师港浸大校园重新焕发生机。

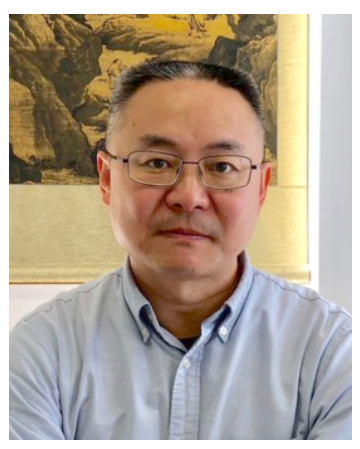

* 郭海鹏, 全人教育办公 室主任, 理工科技学部 计算机科学与技术专业 教授。

Guo Haipeng, Director of Whole Person Education Office; Professor of the Division of Science and Technology. 


\section{一、博雅学院、博雅教育与通识教育}

根据美国学院与大学联盟给出的定义, 博雅学院 ( liberal arts college) 通常是小 而精的住宿学院, 学费昂贵, 小班教学, 师 生互动密切, 且其课程以博雅学科 ( liberal arts ) 为主, 典型的博雅学科包括文学、历 史、哲学、艺术、数学、科学等基础性 学科。

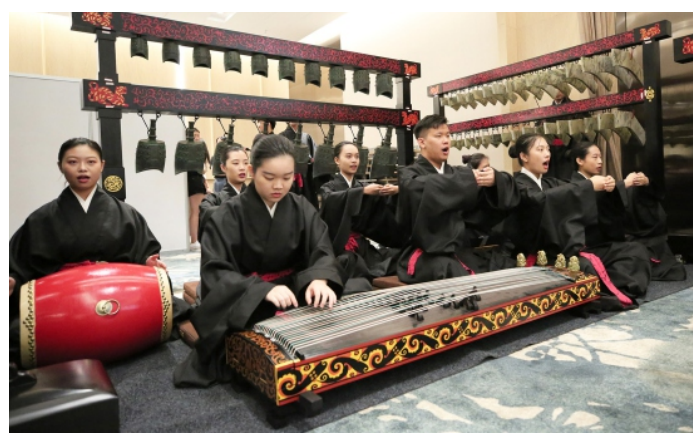

在第五届敬师礼上, 雅乐团开场演奏《木瓜》

博雅学院推行的是一种博雅教育 ( liberal education), 它的宗旨是让学生更 有能力, 帮助他们应对复杂性、多样性和变 化。博雅教育既强调关于广阔世界的知识的 学习, 即通识教育 ( general education), 也强调在某一兴趣领域的深入探究, 即专业 学习 (learning in a special field of study )。博雅教育帮助学生发展其社会责任 感、能为所有专业领域所用的心智的和实际 的技能 (如沟通能力、分析能力和解决问题 的能力）, 以及将知识和技能应用于现实生 活的能力。

博雅教育可以追溯到古希腊教育自 由人 (free man) 的博雅技艺 (artes liberales )，这样的技艺一共有七门，所以 又称博雅七艺（seven liberal arts）。
它们通常分为三文 (trivium) 和四艺 ( quadrivium) 两组，前者包括文法、逻辑 和修辞三个文科科目，后者包括算数、几 何、天文和音乐四个理科科目。因此, 博雅 学院有时又翻译成文理学院。

博雅教育强调一种非功利性的广博的训 练，其对立面是功利性强的职业教育 ( vocational education) 或学习范围比较狭 窄的专业教育 (professional education )。 中世纪欧洲的大学保留了古希腊的博雅七 艺, 只是训练核心由理性转为信仰。随着现 代科学的发展和知识的分化, 大学里开始教 授越来越多专业知识, 博雅教育受到一定的 挤压，古典博雅教育逐步发展成为现代博雅 教育的形式，其课程包括两年的通识教育再 加上两年的专业教育。

通识教育 (general education) 是博雅 教育课程中为全体学生共享的一部分, 它让 各专业的学生能够接触到更广博的学科知 识, 并为学生发展基本的心智、社会参与和 实际应用能力打下基础。通识教育通常包括 人文学科、自然科学和社会科学三大块。

欧美的博雅教育传统在民国时期曾被移 植入中国，其与中国传统 “君子不器” 的教 育理念也有相当的契合度。遗憾的是, 在过 去百多年间, 中国迫于西方坚船利炮的压 力, 逐步对自己的传统文化丧失信心，一步 步切断了悠久的教育传统, 并在五十年代全 盘苏化之后，输入了前苏联一整套培养片面 专才、尤其是工具化理工科专才的教育体制 和理念, 这一影响直到今天仍具主导地位。 不过, 在过去二、三十年间, 随着中国经济 和社会的发展, 博雅教育和通识教育又重新 引起了内地高等教育界的关注, 并在文化素 质教育的概念下，许多零星的、小规模的试 验在各地启动。 


\section{二、全人教育}

全人教育 (whole person or holistic education ) 是香港浸会大学一贯秉持的理

念, 也是北师港浸大创新博雅教育的核心和 灵魂。全人教育是一种以人为本的教育理 念, 旨在培养博雅通达、全面发展的“完整 的人”，即所谓的“全人”。

在西方, 全人教育作为一种带有强烈批 判色彩的“建构性的后现代主义 ( constructive postmodernism) " 教育思 潮，兴起于20世纪60 70年代的美国。自 20 世纪中后叶以来, 人们开始对现代工业文 明带来如环境恶化、生态失衡、核武威胁、 战争频仍、人的异化、消费至上等的种种问 题进行质疑和反思, 意识到需要纠正现代工 业文明过于看重技术理性的功利主义倾向和 相应的教育片面化倾向, 需要重新反思教育 的目的, 从而形成以“追求人的整体发展” 为要旨的全人教育运动。

这一思潮, 一反西方传统关于人性本恶 的假设, 转而认可人性中善之存在; 以有机 整体论 (organic holism) 为其哲学基础, 反 对现代工业文明所持的机械还原论 (mechanistic reductionism) 哲学; 视人和 社会、自然为一有机生命共同体，反对现代 二元论 (dualism) 造成的人与自然的疏离和 人对自然的掠夺和宰制; 视教育和学习为人 内在善性的有机成长和人之潜能的全面发 展, 而非仅仅是工具理性的单向度的发展; 追求达至人与人、人与自然、人与自我的和 谐境界, 以实现对现代工业文明种种弊端的 克服和超越。

在 20 世纪末前后, 全人教育思潮逐步传 播开来, 成为一个世界性的教育改革运动。
联合国教科文组织在1996年发布的《教育, 财富蕴藏其中》的报告中, 特别提出教育的 四个支柱: 学会认知、学会做事、学会共 处、学会做人, 强调教育应当促进每个生命 的整体发展, 包括身体、心理、智力、敏感 性、审美、责任感、精神价值等方面。台湾 在1998年《21世纪教育愿景》中, 提出“全 人教育, 温馨校园, 终身学习”的教育主 轴。香港于 2000 年发表《香港教育制度改革 建议》, 以“终身学习、全人发展”为香港 教育改革的大方向。中国内地也针对应试教 育的弊病, 提出了素质教育的目标。在 2007 年, 中共十七大更是把 “以人为本”

“促进人的全面发展”“构建和谐社会”等 与全人教育理念相一致的各重要概念写入党 章, 成为新时期中国改革的目标。

香港浸会大学的全人教育, 源自基督教 培养“完人”的宗教教育传统。不过在 1983年, 香港浸会大学从一家教会学校转变 为由政府资助的公立学校后, 其全人教育理 念就进行了去宗教化的调整, 宗教色彩大大 弱化。目前香港浸会大学的全人教育强调毕 业生应该具备的七个特质: 公民 ( citizenship) 、知识 (knowledge)、学习 ( learning ) 、技能 (skills)、创意 ( creativity)、沟通 ( communication)、群 体 ( teamwork)。

由于与香港浸会大学的渊源, 北师港浸 大在建校初始就把全人教育作为核心理念, 确立了培育全人的教育目标, 北师港浸大的 全部课程也都是基于浸会大学的七大毕业生 特质设计的。但是, 与香港浸会大学的全人 教育相比, 北师港浸大全人教育的理念和实 践因为是在一个不同的时空中发展起来的, 所以对其既有传承、也有所超越。具体来 讲, 北师港浸大的全人教育没有香港浸会大 
学全人教育的基督教背景, 特别加强了对中 国优秀传统文化的成分, 突出了马克思主义 关于人的全面发展的观点, 以适应本土化的 要求。同时在全人教育学习安排上, 针对中 国传统文化的特点和学生的发展需求做出了 一定调整，形成了独立的课程体系，从而更 加系统化, 更加强调体验式学习 ( experiential learning) 的运用。

\section{三、中国儒家传统中的博雅教育和全 人教育}

中国儒家传统中, 教育的最高目的是养 成君子, 培养圣贤人格。子曰: “君子不 器。” ( 《论语- 为政》) 也就是说, 君子 不能像器具那样, 作用仅仅限于某一方面, 这恰恰与古希腊博雅教育培养“自由人”的 理念若合符节。

同博雅教育一样，全人教育也是中西共 通的教育理念。王国维于1903年提出“人是 知情意的综合体”这一全人定义, 并提出 德、智、体、美四育并举的全人教育模式。 钱穆曾言: “中国教育特所注重, 乃一种全 人教育。所谓全人教育, 乃是其人之内在全 部生命言。贯彻此内在全部生命而为之中心 做主宰者, 乃其人之心情德性。故孔子虽以 六艺教, 而曰志于道、据于德、依于仁、游 于艺。其教人终以道德为重, 才艺为轻。孔 子教育理想, 是一种人的教育, 全人的教 育。孔子教育宗旨, 乃为全人类, 为全人类 中每一人之全生命。此一教育宗旨, 成为中 国教育史上一大趋向。”

孔子所实施的全人教育, 是六经和六艺 之教。六经是《诗》《书》《礼》《易》

《乐》《春秋》的合称, 是指经过孔子整理
而传授的六部先秦古籍。六艺指的是距今三 千年前周朝的贵族教育体系中的六种技能或 六门课程, 包括礼、乐、射、御、书、数, 出自《周礼・保氏》: “养国子以道, 乃教 之六艺：一曰五礼，二曰六乐，三曰五射， 四曰五御, 五曰六书, 六曰九数。”

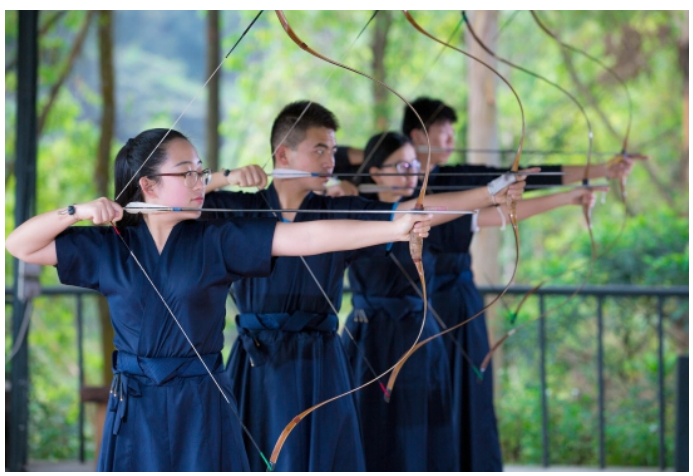

学生练习中华射道

以今天的眼光来看, 六经包括文学、艺 术、哲学、道德、历史等领域的综合知识, 可谓是一种 “古典的通识教育”，而六艺包 括德育、体育、美育、智育、群育等人的全 面发展的多个维度，可谓是一种“古典的全 人教育”。

\section{四、六艺之教在北师港浸大的复兴}

在中国发展博雅教育，必须要既能考虑 到中国悠久的文化传统, 又能照顾到中国的 现实国情, 因此, 必然要发展一种有中国特 色的博雅教育。对经典的研读和对传统的传 承向来是博雅教育的重要组成部分, 有中国 特色的博雅教育必然要包括对中国优秀传统 文化的传承和发扬。先秦的诸子百家, 宋明 的理学, 儒释道的智慧, 历朝历代的文学、 历史、哲学和艺术, 都应该成为有中国特色 
的博雅教育一部分。

从学习方法来说, 中国传统教育一向 重视践履功夫, 强调体认、体知和实践, 提倡主客相融、内外兼修、知行合一的体 验式学习。荀子曰: “不闻不若闻之, 闻之 不若见之, 见之不若知之, 知之不若行 之。学至于行而止矣。行之, 明也。” (《荀子・儒效篇》) 王阳明也倡导 “知 行合一”, 说的都是这个道理。这个特点 应该得到发扬光大, 成为有中国特色的博 雅教育和全人教育一部分。还有, 中国传 统文化中 “修身、齐家、治国、平天下”

“为天地立心、为生民立命、为往圣继绝 学、为万世开太平”的理想, 以及养成仁 爱博大、与天地万物为一体的完整人格的 理念, 都可以成为有中国特色的博雅教育 和全人教育的有机组成部分。此外, 有中 国特色的博雅教育还要兼顾中国的现实国 情, 更加有的放矢。这包括中国独生子女 一代的性格特点, 应试教育的困境, 以及 家庭教育和现实的社会大环境的影响等 等。

基于上述理解, UIC 的全人教育特别注 重对中华优秀传统文化的传承和弘扬, 课 程的设置依照中国传统的修身养性次第展 开, 从“诚意正心”的情绪管理课程, 到 “修身”的艺术体验和体育文化课程, 再 到“齐家治国平天下”服务社会的义工服 务和环境意识课程, 由内向外层层递进。

我们很早就把目光投向了复活孔子的 “六艺”之教, 这既是中国的古典博雅教 育, 也是有中国特色的全人教育。自 2013年起, 我们先后把射道、古琴、雅 乐、书法、成人礼、敬师礼等中华传统礼
乐教育的核心学习体验以课程或活动的形 式引入北师港浸大校园。2019年6月, 还首 次试水马术课程, 引起省内外媒体的广泛 关注, 报道中称 “古代“六艺”在这里集 齐”。2019年7月, 在陈致学术副校长的领 导推动下, 我们也首次尝试面向中学生开 展“中华文化国际英才夏令营”，把各种 有中国传统文化特色的全人教育课程推广 到初中和高中生, 得到家长和同学的一致 好评, 也扩大了学校的知名度。

\section{五、结语}

一般而言, 西方文化强调崇真和求 知, 是一种 “知识的学问”, 中国文化强调 向善和做人, 是一种 “生命的学问”, 北师 港浸大的创新博雅教育和全人教育力图融合 中西文化的长处, 既注重教学生如何求知, 更注重教学生如何做人。正如北师港浸大校 歌所唱: “融中西思想, 通古今文章”。校 训 “博文雅志, 真知笃行”, 也明确兼顾求 知与做人这两个方面: “博文”与 “真知” 是属于知识了解方面, “雅志”与 “笃行” 是属于德性行为方面的。北师港浸大的校训 也可以说是代表了北师港浸大的精神, 既旁 采了西方博雅教育的精神, 也能上溯至中国 宋明书院精神乃至于中国文化源头里孔孟之 教的真精神。值此国家进入新时代, 北师港 浸大也进入发展新阶段的重要时刻, 愿以校训“博文雅志, 真知笃行 $(\mathrm{In}$ knowledge and in deeds, unto the whole person) " 与君共勉, 祝北师港浸大更上 一层楼! 픈 